\title{
A lição de sabedoria das vacas loucas
}

\author{
CLAUDE LÉVI-STRAUSS
}

$\mathrm{P}$ ARA OS AMERÍNDIOS e a maior parte dos povos que viveram muito tempo sem escrita, o tempo dos mitos foi aquele em que os homens e os animais não eram realmente distintos uns dos outros e podiam se comunicar entre si. Fazer começar os tempos históricos com a torre de Babel, quando os homens perderam o uso de uma língua comum e deixaram de se compreender, lhes teria parecido uma visão estranhamente acanhada das coisas. Para eles, esse fim de uma harmonia primitiva se deu num âmbito bem mais vasto; ele atingiu não somente os homens, mas todos os seres vivos.

Ainda hoje, é como se continuássemos confusamente conscientes dessa solidariedade primeira entre todas as formas de vida. Nada nos parece mais urgente do que imprimir, desde o nascimento ou quase, o sentimento dessa continuidade no espírito de nossas crianças. Cercamo-las de simulacros de animais de plástico ou de pelúcia, e os primeiros livros de imagens que colocamos sob seus olhos lhes mostram, bem antes que os conheçam, o urso, o elefante, o cavalo, o burro, o cachorro, o gato, o galo, a galinha, o rato, o coelho etc., como se fosse preciso, desde a mais tenra idade, lhes dar a nostalgia de uma unidade que em breve elas saberão terminada.

Não é surpreendente que matar seres vivos para se alimentar coloque aos humanos, tenham eles consciência ou não desse fato, um problema filosófico que todas as sociedades tentaram resolver. O Antigo Testamento faz dele uma consequência indireta da queda. No jardim do Éden, Adão e Eva se alimentavam de frutos e sementes (Gênesis I: 29). Foi somente a partir de Noé que o homem se tornou carnívoro (IX: 3). É significativo que essa ruptura entre o gênero humano e os outros animais preceda imediatamente a história da torre de Babel, isto é, a separação dos homens uns dos outros, como se essa fosse a consequência ou um caso particular daquela.

Essa concepção faz da alimentação carnívora uma espécie de enriquecimento do regime vegetariano. Ao contrário, alguns povos sem escrita veem nela uma forma muito pouco atenuada de canibalismo. Eles humanizam a relação entre o caçador (ou o pescador) e sua presa, concebendo-a segundo a relação de parentesco entre aliados pelo casamento ou, mais diretamente ainda, entre cônjuges (assimilação facilitada por aquela que todas as línguas do mundo, e mesmo as nossas em expressões da gíria, fazem entre o ato de comer e o ato de copular). A caça e a pesca aparecem assim como um tipo de endocanibalismo. 
Outros povos, às vezes também os mesmos, julgam que a quantidade total de vida existente a cada momento no universo deve sempre ser equilibrada. O caçador ou o pescador que lhe retira uma fração deverá, se podemos dizer, reembolsá-la à custa de sua própria expectativa de vida. É outra maneira de ver na alimentação carnívora uma forma de canibalismo: autocanibalismo dessa vez, pois, segundo essa concepção, comemos a nós mesmos ao acreditar comer um outro.

Há cerca de três anos, a propósito da epidemia dita da vaca louca, que então não tinha tanta atualidade quanto hoje, expliquei aos leitores de La Repubblica num artigo ("Siamo tutti canibali", 10-11 de outubro de 1993) que as patologias vizinhas que vitimavam às vezes o homem - kuru na Nova-Guiné, casos novos da doença de Creutzfeldt-Jacob na Europa (resultante da administração de extratos de cérebro humano para tratar distúrbios de crescimento) - estavam ligadas a práticas relacionadas em sentido próprio ao canibalismo, cuja noção se devia ampliar para poder incluir todas elas. E eis que ficamos sabendo agora que a doença da mesma família que atinge as vacas em vários países europeus (e que apresenta um risco mortal para o consumidor) é transmitida pela farinha de origem bovina com que esses animais eram alimentados. Portanto, ela resultou da transformação deles, pelo homem, em canibais, segundo um modelo, aliás, que não é sem precedente na história. Textos da época afirmam que, durante as guerras de Religião que ensanguentaram a França no século XVI, os parisienses famintos foram obrigados a se alimentar de um pão à base de farinha feita de ossadas humanas extraídas das catacumbas e moídas.

A ligação entre a alimentação carnívora e um canibalismo mais amplo, com uma conotação universal, tem assim, no pensamento, raízes muito profundas. Ela volta ao primeiro plano com a epidemia das vacas loucas, pois ao temor de contrair uma doença mortal se acrescenta o horror que nos inspira tradicionalmente o canibalismo, estendido agora aos bovinos. Condicionados desde a primeira infância, continuamos certamente carnívoros e nos desviamos para carnes de substituição. Mesmo assim o consumo de carne baixou de forma espetacular. Mas, bem antes desses acontecimentos, quantos de nós podíamos passar diante da vitrina de um açougue sem sentir um mal-estar, ao vê-la por antecipação na óptica de futuros séculos? Pois chegará um dia em que a ideia de que os homens do passado, para se alimentar, criavam e massacravam seres vivos e expunham complacentemente sua carne em pedaços nas vitrinas inspirará por certo a mesma repulsa que, para os viajantes dos séculos XVI ou XVII, as refeições canibais dos selvagens americanos, africanos ou australianos.

A voga crescente dos movimentos de defesa dos animais é uma prova disso: percebemos cada vez mais distintamente a contradição na qual nossos costumes nos encerram, entre a unidade da criação, tal como se manifestava ainda na entrada da arca de Noé, e sua negação pelo próprio Criador, na saída.

Entre os filósofos, Augusto Comte é provavelmente um dos que mais 
deram atenção ao problema das relações entre o homem e o animal. Ele o fez de uma forma que os comentadores preferiram ignorar, atribuindo-a a uma daquelas extravagâncias frequentes nesse grande gênio. Ela merece, porém, ser examinada.

Comte divide os animais em três categorias. Na primeira coloca os que, de uma maneira ou de outra, apresentam para o homem um perigo, e propõe simplesmente destruí-los.

Numa segunda categoria, ele reúne as espécies protegidas e criadas pelo homem para se alimentar: bovinos, ovinos, porcos, aves de galinheiro... Desde milênios o homem transformou tão profundamente esses animais que nem se pode mais chamá-los assim. Devem-se ver neles os "laboratórios nutritivos" nos quais se elaboram os compostos orgânicos necessários à nossa subsistência.

Se Comte expulsa essa segunda categoria da animalidade, ele integra a terceira à humanidade. Essa agrupa as espécies sociáveis em que encontramos companheiros e muitas vezes até auxiliares ativos: animais cuja "inferioridade mental muito se exagerou". Alguns, como o cachorro e o gato, são carnívoros. Outros, por sua natureza de herbívoros, não têm um nível intelectual suficiente que os torne utilizáveis. Comte preconiza transformá-los em carnívoros, o que de modo nenhum lhe parece impossível, uma vez que na Noruega, quando falta forragem, o gado é alimentado com peixe seco. Com isso, alguns herbívoros seriam levados ao mais alto grau de perfeição que a natureza animal comporta. Tornados mais ativos e mais inteligentes por seu novo regime alimentar, passariam a se devotar melhor a seus mestres, a se comportar como servidores da humanidade. Poderia ser-lhes confiada a principal vigilância das fontes de energia e das máquinas, deixando assim os homens disponíveis para outras tarefas. Comte reconhece que é uma utopia, mas não mais que a transmutação dos metais que, no entanto, está na origem da química moderna. Ao aplicar a ideia de transmutação aos animais, não se faz senão estender a utopia da ordem material à ordem vital.

Essas ideias, velhas de um século e meio, são proféticas em vários aspectos, ao mesmo tempo que oferecem, em outros, um caráter paradoxal. Sabemos muito bem que o homem provoca direta ou indiretamente o desaparecimento de inúmeras espécies e que outras estão, por culpa dele, gravemente ameaçadas. Que se pense nos ursos, lobos, tigres, rinocerontes, elefantes, baleias etc., mais as espécies de insetos e outros invertebrados que as degradações infligidas pelo homem ao ambiente natural aniquilam dia a dia.

Profética também, e num ponto que Comte não teria podido imaginar, é a visão dos animais de que o homem faz seu alimento, impiedosamente reduzidos à condição de laboratórios nutritivos. A criação em massa de bezerros, leitões e frangos oferece a ilustração mais horrível desse fato, que sensibilizou até mesmo, recentemente, o Parlamento europeu.

Profética, enfim, é a ideia de que os animais que formam a terceira categoria concebida por Comte serão para o homem colaboradores ativos, como o 


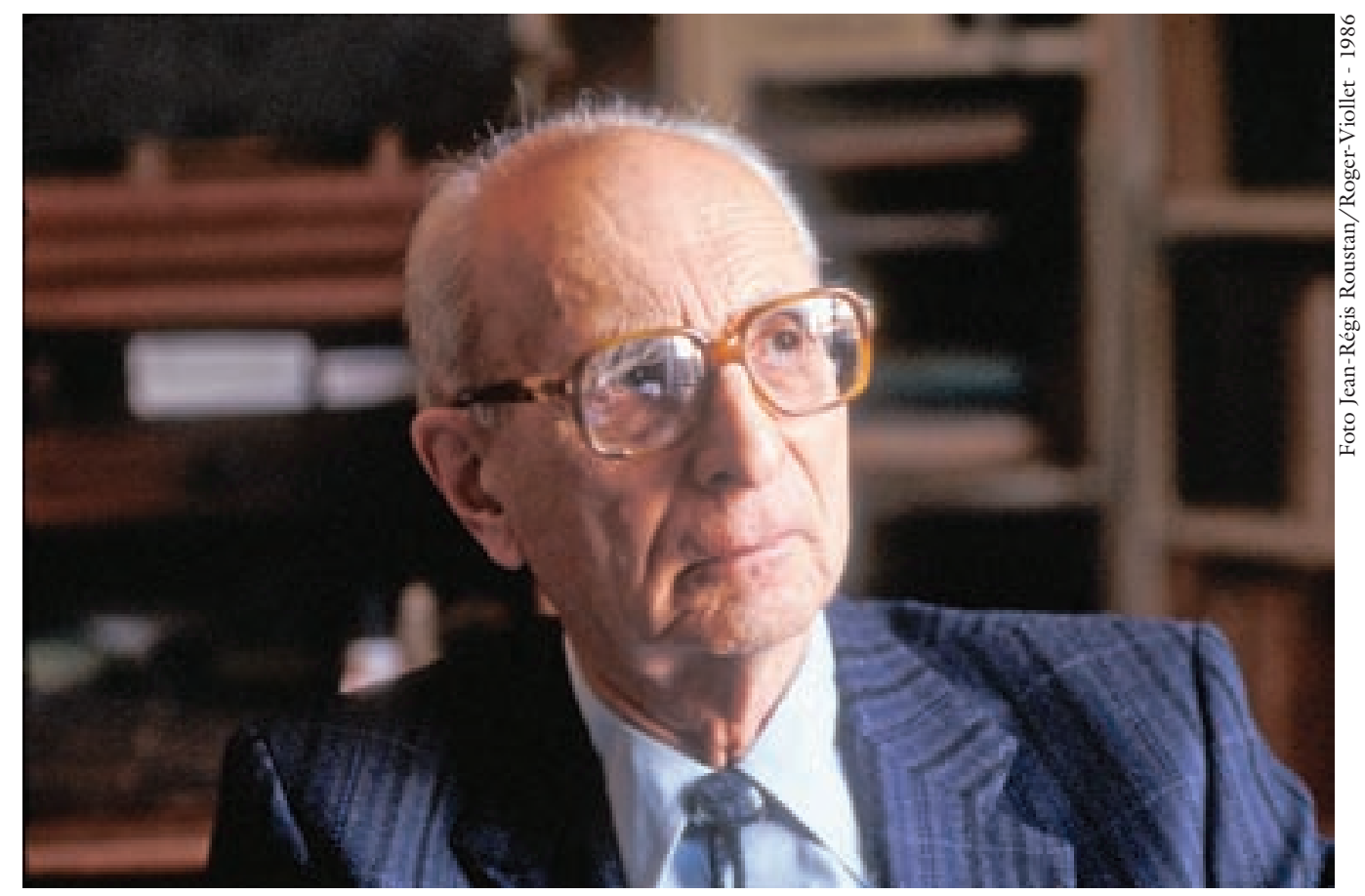

Lévi-Strauss completou 100 anos de idade em 28 de novembro de 2008.

atestam as missões cada vez mais diversas confiadas a cães adestrados, o recurso a macacos especialmente formados para assistir inválidos, as esperanças que os golfinhos ensejam.

A transmutação de herbívoros em carnívoros é igualmente profética, como o prova o drama das vacas loucas, mas nesse caso as coisas não se passaram da maneira prevista por Comte. Se transformamos herbívoros em carnívoros, essa transformação talvez não seja, em primeiro lugar, tão original quanto acreditamos. Chegou-se a afirmar que os ruminantes não são verdadeiros herbívoros, pois se alimentam sobretudo de micro-organismos que, por sua vez, se alimentam dos vegetais por fermentação num estômago especialmente adaptado.

Essa transformação, sobretudo, não se fez em proveito dos auxiliares ativos do homem, mas em detrimento dos animais qualificados por Comte de laboratórios nutritivos: erro fatal contra o qual ele próprio havia prevenido, pois, dizia, "o excesso de animalidade lhes seria prejudicial". Prejudicial não só para eles, mas para nós: pois não foi ao lhes conferir um excesso de animalidade (fazendo deles canibais, bem mais do que carnívoros) que transformamos, involuntariamente, é verdade, nossos "laboratórios nutritivos" em laboratórios mortíferos?

A doença da vaca louca ainda não atingiu todos os países. A Itália, acredito, até agora está imune. É possível que a esqueçam em breve: ou porque a epidemia se extinguirá por si própria, como predizem os cientistas britânicos, ou porque descobrirão vacinas ou curas, ou ainda porque uma política sanitária rigorosa garantirá a saúde dos animais destinados ao abate. Mas outros roteiros são também concebíveis. 
Suspeita-se que, contrariamente às ideias aceitas, a doença poderia transpor as fronteiras biológicas entre as espécies. Atingindo todos os animais dos quais nos alimentamos, ela se instalaria de forma duradoura e passaria a fazer parte dos males nascidos da civilização industrial, que comprometem cada vez mais gravemente a satisfação das necessidades de todos os seres vivos.

Já respiramos um ar poluído. A água, igualmente poluída, não é mais aquele bem que podíamos acreditar disponível sem limite: sabemos que há restrições tanto para a agricultura quanto para o uso doméstico. Desde o aparecimento da Aids, as relações sexuais comportam um risco fatal. Todos esses fenômenos perturbam e perturbarão de forma profunda as condições de vida da humanidade, anunciando uma nova era na qual se instalaria, em continuidade, esse outro perigo mortal que seria agora a alimentação carnívora.

Aliás, esse não é o único fator que poderia obrigar o homem a afastar-se dela. Num mundo em que a população global terá provavelmente dobrado em menos de um século, o gado e os outros animais de criação se tornam para o homem temíveis concorrentes. Calculou-se que, nos Estados Unidos, dois terços dos cereais produzidos servem para alimentá-los. E não esqueçamos que esses animais nos dão em forma de carne muito menos calorias que as que eles consumiram durante sua vida (um quinto, me disseram, no caso de um frango). Uma população humana em expansão logo terá necessidade, para sobreviver, da produção cerealífera atual inteira: nada restará para a criação de gado e de aves, de modo que todos os humanos deverão seguir o regime alimentar de indianos e chineses, no qual a carne animal cobre uma parte muito pequena das necessidades de proteínas e calorias. Talvez seja preciso até renunciar completamente a ela, pois, à medida que a população aumenta, a superfície das terras cultiváveis diminui sob o efeito da erosão e da urbanização, as reservas de hidrocarbonetos baixam e os recursos em água se reduzem. Em contrapartida, os especialistas calculam que, se a humanidade se tornasse integralmente vegetariana, as superfícies hoje cultivadas poderiam alimentar o dobro da atual população.

É notável que, nas sociedades ocidentais, o consumo de carne tenda espontaneamente a diminuir, como se essas sociedades começassem a mudar de regime alimentar. Nesse caso, a epidemia da vaca louca, ao desviar os consumidores de carne, estaria acelerando uma evolução em curso. Ela apenas lhe acrescentaria um componente místico feito do sentimento difuso de que a nossa espécie paga por ter infringido a ordem natural.

Os agrônomos se encarregarão de fazer aumentar o teor proteico das plantas alimentares, os químicos, de produzir em quantidade industrial proteínas sintéticas. Mas, ainda que a encefalopatia espongiforme (nome científico da doença da vaca louca e de outras aparentadas) se instale de forma duradoura, apostamos que o apetite pela carne nem por isso desaparecerá. Sua satisfação se tornará apenas uma ocasião rara, custosa e cheia de risco. (O Japão conhece algo parecido com o fugu, peixe tetrodontídeo de um sabor requintado, dizem, mas 
que, inadequadamente eviscerado, pode ser um peixe mortal.) A carne figurará no cardápio em circunstâncias excepcionais. Será consumida com a mesma mistura de reverência piedosa e de ansiedade que, segundo os antigos viajantes, impregnava as refeições canibais de certos povos. Em ambos os casos, trata-se ao mesmo tempo de comungar com os antepassados e de incorporar, com seus riscos e perigos, a substância de seres vivos que foram ou se tornaram inimigos.

Tendo desaparecido completamente a criação de gado, não rentável, essa carne comprada em lojas de grande luxo há de provir apenas da caça. Nossos antigos rebanhos, entregues a si mesmos, serão uma caça como outra qualquer num campo devolvido à selvageria.

Assim, não se pode afirmar que a expansão de uma civilização que se pretende mundial uniformizará o planeta. Ao amontoar-se, como vemos hoje, em megalópoles tão grandes como províncias, uma população antes mais distribuída esvaziará outros espaços. Definitivamente abandonados por seus habitantes, esses espaços retornariam a condições arcaicas e neles, aqui e ali, as mais estranhas formas de vida se instalariam. Em vez de marchar para a monotonia, a evolução da humanidade acentuaria os contrastes e criaria até mesmo novos, restabelecendo o reinado da diversidade. Rompendo com hábitos milenares, tal é a lição de sabedoria que teremos um dia aprendido, talvez, com as vacas loucas.

Artigo publicado em italiano em La Repubblica, 24 de novembro de 1996, e em francês em Études Rurales, janeiro-junho de 2001, p.157-8: p.9-14.

Publicado em Hors Série - La Lettre du Collège de France, Claude Lévi-Strauss - Centième anniversaire, Novembre 2008. Tradução de Paulo Neves. O original em francês - "La leçon de sagesse des vaches folles" - encontra-se à disposição do leitor no IEAUSP para eventual consulta.

Recebido em 16.7.2009 e aceito em 21.8.2009. 